University of Chicago Law School

Chicago Unbound

Journal Articles

Faculty Scholarship

2003

\title{
Probability Errors: Some Positive and Normative Implications for Tort and Contract Law
}

Eric A. Posner

Follow this and additional works at: https://chicagounbound.uchicago.edu/journal_articles

Part of the Law Commons

\section{Recommended Citation}

Eric Posner, "Probability Errors: Some Positive and Normative Implications for Tort and Contract Law," 11 Supreme Court Economic Review 125 (2003).

This Article is brought to you for free and open access by the Faculty Scholarship at Chicago Unbound. It has been accepted for inclusion in Journal Articles by an authorized administrator of Chicago Unbound. For more information, please contact unbound@law.uchicago.edu. 


\title{
Probability Errors: Some Positive and Normative Implications for Tort and Contract Law
}

\author{
Eric A. Posner*
}

This paper examines the effect of tort rules on behavior if people are optimistic or insensitive relative to true probabilities. The paper shows that under certain conditions both strict liability and negligence cause levels of care that are higher than, or equal to, what is efficient (rather than lower, which is the common assumption). The paper also shows that under certain conditions strict liability and negligence cause the same level of activity among optimists (more than is efficient). Other implications for tort law are discussed, as are the sensitivity of the results to the choice of how to model probability errors. Implications for contract law, and some normative issues, are also discussed.

\section{INTRODUCTION}

Evidence from experiments and empirical studies suggests that people make systematic errors when they estimate probabilities. The exact nature of these errors remains controversial, but two themes are that people discount low probability events, treating them as though they occur with a probability of zero, and that, more generally, people are insensitive to small differences between probabilities. The first bias might cause a homeowner to treat the probability of a remote event

*Kirkland \& Ellis Professor of Law, University of Chicago. Thanks to Oren Bar-Gill, Omri Ben-Shahar, Bill Landes, Doug Lichtman, Anup Malani, Francesco Parisi, John Pfaff, Steve Shavell, Al Sykes, David Weisbach, and participants in this conference and at a seminar at the University of Virginia Law School, for comments, and to The Sarah Scaife Foundation Fund and The Lynde and Harry Bradley Foundation Fund, for financial support.

(C) 2004 by the University of Chicago. All rights reserved. 0-226-64593-2/2004/0011-0003\$10.00 
like an earthquake as though it were equal to zero; the second bias might cause a person to divide potential accidents into a small number of categories-high, medium, and low. I will follow the literature and call the first problem one of "optimism," though, as we shall see, this term is imprecise; and I will call the second problem one of "insensitivity."1

Legal scholars think that optimism and probability insensitivity justify additional regulation because optimists will take too little care. If the driver of an automobile believes that the risk of an accident is zero, he will drive too quickly. But the truth turns out to be more complex. A person who discounts remote risks might take too much care, rather than too little. By increasing his level of care incrementally, the person can reduce his perceived probability of an accident non-incrementally, from some positive amount to zero. If the perceived reduction in expected accident costs exceeds the cost of the additional care, the person will use more care than is efficient, and this is true regardless whether the legal rule is strict liability or negligence.

This result holds as well for people who suffer from probability insensitivity. Even if they do not treat low probability events as though they would occur with probability of zero, they will enjoy large perceived benefits when they can take a small amount of additional care in order to move the risk of an accident from the "high" category to "medium," or "medium" to "low." The existence of discontinuities or inflexion points in probability functions plays havoc with intuitions about the relationship between the law and decisions about care level.

This paper explores these and other implications of optimism and insensitivity for the law. ${ }^{2}$ Part I focuses on optimism and tort law. My other main result is that sufficiently optimistic agents engage in the same level of activity under strict liability and negligence; by contrast, rational agents engage in more activity under strict liability

${ }^{1}$ I am aware that the evidence is ambiguous, that these phenomena might be sensitive to context and limited by offsetting biases or cognitive strategies, and so forth, but I set aside these questions for the purposes of analysis.

${ }^{2}$ The law and economics literature does address error and misperception, but in a different context. For discussions of error by courts, see Richard Craswell \& John E. Calfee, Deterrence and Uncertain Legal Standards, 2 J L, Econ, \& Org 279 (1986); Steven Shavell, Economic Analysis of Accident Law 79-83 (Harvard 1987); of misperceptions of the effect of care on expected liability, see Peter A. Diamond, Single Activity Accidents, 3 J Legal Stud 107 (1974); the use by courts of information about products that was not available to the producer, see Omri Ben-Shahar, Should Procuts Liability Be Based on Hindsight?, 14 J L, Econ, \& Org 325 (1998); and relatedly, of the effect of judgment-proofness and causation requirements on incentives, see William M. Landes and Richard Posner, The Economic Structure of Tort Law (Harvard 1987). There is also a related literature on consumer protection and misperception; see Richard M. Hynes and Eric A. Posner, The Law and Economics of Consumer Finance, 4 Am L \& Econ Rev 162 (2002), for a survey. 
than under negligence. The reason for this difference is that the optimistic agent under strict liability and the rational agent under negligence do not internalize accident costs when they take due care (or what they think is due care). I also discuss the difference between harm-sensitive and harm-insensitive optimism; the relationship between optimism and probability insensitivity; and the implications of optimism for bilateral accidents. Part II briefly discusses optimism and contract law, and Part III contains some general comments about the treatment of probability errors in normative law and economics.

\section{PROBABILITY ERRORS AND TORT LAW}

\section{A. Summary of Analysis}

Suppose that agents are rational except that they are optimistic about low probability accidents. When they engage in some behavior like driving, they know that their behavior creates a risk of harm. When choosing the level of care, agents know the actual probability of harm associated with each level of care when the probability is above some threshold; below that threshold the probability of harm, which is low but positive, is treated as though it were zero.

Intuition tells us that such an agent would take too little care, whether the tort regime is strict liability or negligence. The analysis will show that for sufficiently high levels of optimism, the agent might take too much or too little care. The effect that causes too little care is the discounting of harms: the agent underestimates expected liability for a high level of care, and so will take less care. The effect that causes too much care is that the agent can cause a (subjective, that is, error-driven) reduction of expected liability by taking a small amount of additional care. If the agent takes some level of care that causes a perceived positive probability of harm, and if a small additional amount of care would cause that probability to drop from the threshold amount to zero, then the agent will think that he is, in effect, taking a small extra precaution that will eliminate all potential liability. Which of the effects dominates depends on the relationship between the probability distribution, the level of harm, and the care function. Optimism could cause an agent to think that a bad event will not occur, or that a little extra care will have a dramatic effect on the probability of a bad event occurring.

In addition, for sufficiently low levels of optimism, the agent will take the optimal care, and this amount of care is invariant with respect to the amount of optimism below a threshold. The agent does not take too much care because the amount of care necessary to create zero perceived expected harm is greater than the sum of the cost 
of optimal care and the correctly perceived expected harm. The agent does not take too little care because at the optimal level of care an accident is risky enough to be accurately anticipated by the lowoptimism agent.

A well known result in the literature is that for unilateral accidents, strict liability and negligence have the same effect on care, but different effects on the level of activity. Strict liability causes the efficient level of activity; negligence causes too much activity. However, the difference between the two rules nearly disappears when the agent is optimistic. Both rules cause too much activity; indeed, unless the risk is sufficiently remote, the two rules cause the same level of inefficient activity. The reason is that under both regimes the optimistic agent will treat remote events as though they do not occur, and so the main difference between strict liability and negligencenamely, that under negligence the agent is not liable if he takes due care-disappears in the agent's mind.

Next, I show informally that the results can hold even under less extreme assumptions about probability misestimation. The factor that drives the results is not the possibility that people could treat certain probabilities as though they were zero, but the possibility that people have trouble thinking of probability distributions as smooth or continuous functions and divide lower and higher probability events into discrete groups.

Finally, I argue that for bilateral accidents the different effects of strict liability and negligence on rational individuals carry over to the case of optimism: both rules cause the injurer to take care but only negligence causes the victim to take care. However, under both rules the level of care taken by injurer and victim will not be optimal. As for activity level, the different effects of strict liability with contributory negligence, and negligence, on rational individuals do not carry over to the case of optimism. Strict liability with contributory negligence encourages rational victims but not rational injurers to engage in too much activity; negligence encourages rational injurers but not rational victims to engage in too much activity. By contrast, the two rules have the same effect on optimistic injurers and victims, encouraging both groups to engage in too much activity.

\section{B. Analysis}

\section{Level of Care.}

Let: $x=$ level of care (normalized, so $\mathrm{x}$ is also the cost of care); $p(x)$ be the probability of an accident, as a function of the level of care $\left(p^{\prime}|x|\right.$ $\left.<0 ; p^{\prime \prime}(x)>0\right) ; h=$ harm. For illustrative purposes, we assume that $p(x)$ 


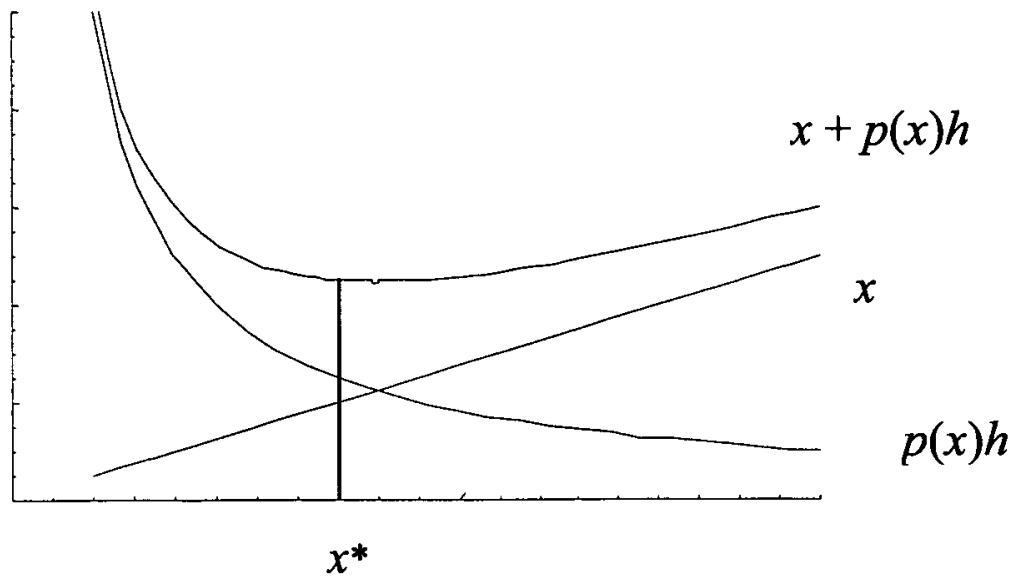

Figure 1.

$=x^{-2}$. For simplicity harm is a constant: the agent controls only the probability of the harm occurring.

The total (that is, social) cost function, $T C=x+x^{-2} h$. The optimal level of care $x^{\star}=(2 h)^{1 / 3}$.

Strict liability will cause the agent to choose $x^{\star}$; negligence will cause the agent to choose $x^{\star}$ if (for example) the agent must pay $h$ if $x<x^{\star}$. Figure 1 illustrates these standard results. ${ }^{3}$

Now we want to ask what happens if the agent has an irrational probability function $p^{i}(x)$, where

$$
\begin{aligned}
p^{i}(x) & =x^{-2} \text { if } p(x)>\bar{p} \\
& =0 \text { otherwise. }
\end{aligned}
$$

The value of $\bar{p}$ refers to the floor below which the probability of the accident is so small that the agent treats it as if it were 0 .

Corresponding to $\bar{p}$ is a level of care, $x^{\prime}$, which is the threshold between levels of care associated with accurate probability assessments and levels of care associated with optimistic probability assessment. To determine the value of $x^{\prime}$, we must first make an additional assumption about whether the agent's optimism is sensitive to the level of harm or not. Consider the driver of an ordinary truck and the driver of a tanker truck filled with gasoline. One could imagine that each driver is equally insensitive to a low probability accident for a given level of care $x$, where $p(x)<\bar{p}$, but one could also imagine that the

${ }^{3}$ See John Prather Brown, Toward an Economic Theory of Liability, 2 J Legal Stud 323 (1973); Shavell, Economic Analysis of Accident Law (cited in note 2); Landes and Posner, The Economic Structure of Tort Law (cited in note 2). 
driver of the tanker is more sensitive. In the first (harm-insensitive) case, $p^{i}(x)=x^{-2}$ if $p(x)>\bar{p}$, so $x^{\prime}=(1 / \bar{p})^{1 / 2}$. In the second (harm-sensitive) case, $p^{i}(x)=x^{-2}$ if $p(x)>\bar{p} / h$, so $x^{\prime}=\left(h /\left.\bar{p}\right|^{1 / 2}\right.$. I will assume that optimism is harm-sensitive, which seems more realistic, but will briefly discuss the harm-insensitive case in Section I.B.3.

The agent will minimize $T C^{i}=x+p^{i}(x) h$. There are two separate cases to consider. First, if $\bar{p}$ is sufficiently low, and thus $x^{\prime}$ is sufficiently high, the agent will choose $x^{i}=x^{\star}$. The reason is that the level of care necessary to reach $x^{\prime}$ is higher than the combined care and accident costs for $x^{\star}$. Think of a driver who believes that he can reduce the probability of an injury to zero only by driving a Volvo but the ownership cost of a Volvo is greater than the joint cost of owning a Honda and expected liability from an accident. The driver will not buy the Volvo but will buy the Honda and take efficient care.

Second, if $\bar{p}$ is not too low, and thus $x^{\prime}$ is not too high, $x^{i}=x^{\prime}$. This is the case where the ownership cost of the Volvo, and thus the illusory sense of never being liable, is less than the combined ownership and expected accident costs of the Honda.

To find the dividing line between the two cases, one sets the cost of the "irrational" level of care that generates illusory expected zero liability (Volvo) equal to the joint care and accident costs for rational care (Honda): $T C\left(x^{\prime}\right)=T C\left(x^{*}\right)$. Because $T C\left(x^{\prime}\right)=x^{\prime}$ (the expected accident cost is zero), we have: $x^{\prime}=(h / \bar{p})^{1 / 2}=T C\left(x^{*}\right)=(3 h)^{1 / 3} / 2^{2 / 3}$. Simplifying:

$$
\begin{gathered}
x^{i}=x^{\star} \text { if } \bar{p} \leq 2^{4 / 3} h^{1 / 3} / 9 \approx 0.27 h^{1 / 3} \\
x^{\prime} \text { otherwise }
\end{gathered}
$$

If we limit ourselves to the second case, where $x^{i}=x^{\prime}$, then we can ask whether $x^{i}$ is greater than or less than $x^{\star}$. Setting $x^{i}=x^{*}$, we get $\bar{p}=$ $h^{1 / 3} / 2^{2 / 3} \approx 0.63 h^{1 / 3}$. It turns out that it could be either.

If $\bar{p}<0.63 h^{1 / 3}$, then $x^{i}>x^{\star}$.

If $\bar{p} \geq 0.63 h^{1 / 3}$, then $x^{i} \leq x^{*}$.

Thus there are three regions:

In the first region, the probability threshold (where the agent treats the probability of the event as though it were zero) is so remote, that the agent would need to incur a lot of care in order to reach it. Because

Table 1

\begin{tabular}{lll}
\hline Low Optimism & Moderate Optimism & High Optimism \\
\hline $\bar{p} \leq 0.27 h^{1 / 3}$ & $0.27 h^{1 / 3}<\bar{p}<0.63 h^{1 / 3}$ & $0.63 h^{1 / 3} \leq \bar{p}$ \\
$X^{i}=x^{*}$ & $x^{i}=x^{\prime}>x^{*}$ & $x^{i}=x^{\prime} \leq x^{*}$ \\
Optimal Care & Too Much Care & Too Little Care \\
\hline
\end{tabular}




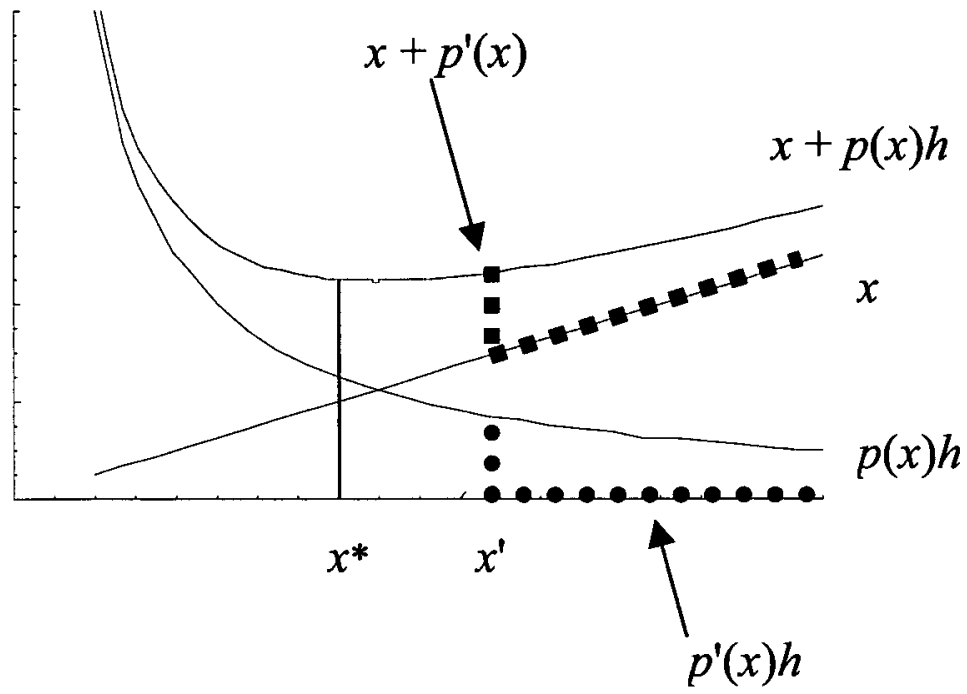

Figure 2.

the cost of care is so high, the agent would prefer choosing the level of care that minimizes the "rational" total cost function. This is the example where the agent buys the Honda rather than the Volvo.

In the second region, the probability threshold is not so remote, so the agent finds it worthwhile to take extra care in order to reduce expected accident cost from a positive amount to an amount he perceives as 0 . See Figure 2. The optimal level of care while driving is, let's suppose, a good night's sleep and driving during the day; but the agent thinks that if he does these things and buys antilock breaks he will never have an accident. He takes too much care because the extra precaution creates the illusory sense of no expected liability.

In the third region, an inefficiently low level of care is sufficient to reach the probability threshold, and the agent has no incentive to take additional care. See Figure 3. The agent thinks that a good night's sleep is sufficient to reduce the probability of an accident to zero; therefore, he does not bother confining his driving to the day.

Figure 4 shows care as a function of optimism. For low levels of optimism, care is $\mathrm{x}^{\star}$. Above $\bar{p}=0.27 \mathrm{~h}^{1 / 3}$, care is a declining function of optimism.

Negligence. We have assumed strict liability, but what about negligence? If the agent assumes that courts will set the level of due care at $x^{i}$ rather than $x^{\star}$, then the results remain the same. The agent will take too little care or too much care, depending on $\bar{p}$ and $h$. Thus, the agent has the same care incentives under strict liability and negligence. 


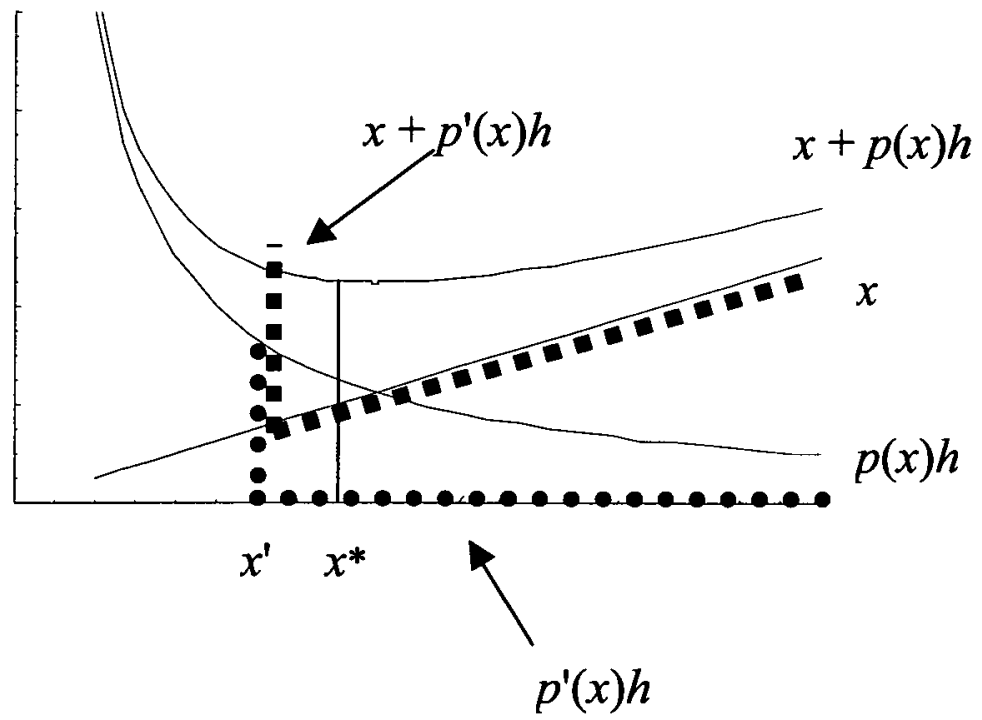

Figure 3.

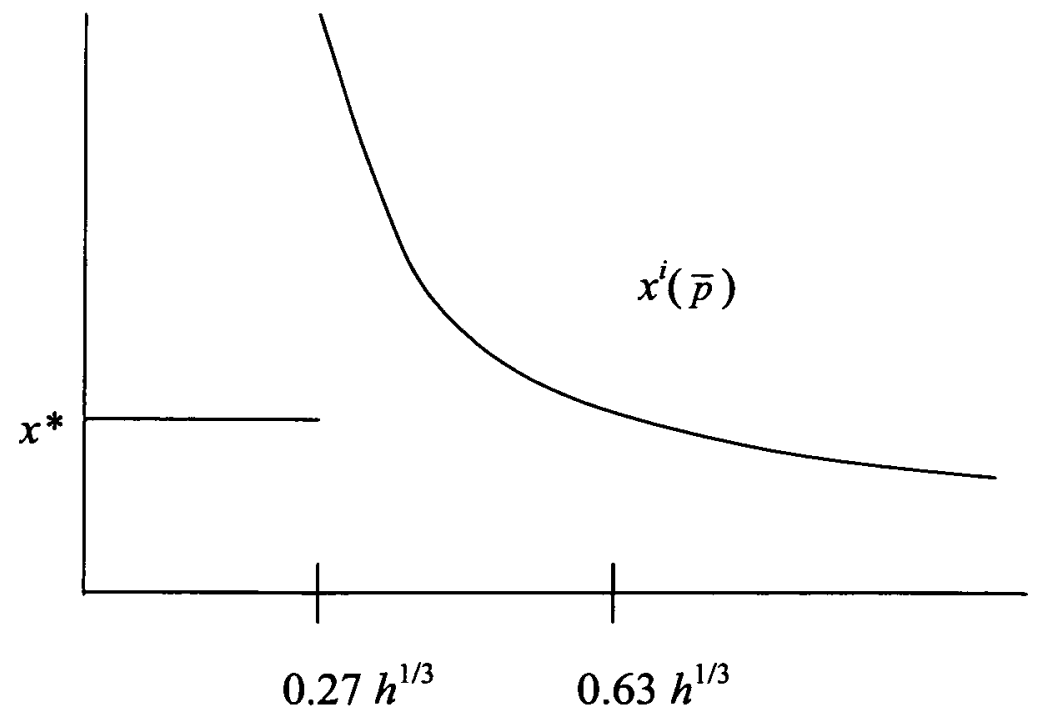

Figure 4. 
But there is another possibility. If the agent believes that the court (irrationally!) will insist on setting the due care level at $x^{*}$, then the agent's behavior under negligence and strict liability will differ but only in the midlevel optimism case. In the latter case, the agent will prefer to incur the cost of optimal care $x^{*}$, rather than too much care, $x^{\prime}$, because $x^{\star}<x^{\prime}$. Under negligence, the agent does not bear expected accident costs if he takes level of care $x^{*}$, so he gains nothing by increasing the level of care to $x^{\prime}$.

\section{Activity Level.}

Now suppose that the agent can choose his level of activity. Let $s=$ level of activity, and $u(s)$ equal the agent's level of utility from engaging in a certain level of activity $\left(u^{\prime}(s)>0, u^{\prime \prime}(s)<0\right)$. Then the utility function is: $u(s)-s x-s p(x) h=u(s)-s(x+p(x) h)$. The agent maximizes utility by minimizing the value of the negative expression, which means choosing optimal care $x^{\star}$; and then by choosing an activity level $s^{\star}$ that maximizes utility given the per-unit joint cost of care and expected liability. ${ }^{4}$

Using our earlier probability function, $p(x)=x^{-2}$, it follows that utility is maximized if $x^{\star}=(2 h)^{1 / 3}($ minimizing the negative expression) and if $s^{\star}$ is such that $u^{\prime}(s)=(2 h)^{1 / 3}+\left((2 h)^{1 / 3}\right)^{-2} h=(3 h)^{1 / 3} / 2^{2 / 3}$.

Now let us look at the agent's incentives if he uses optimistic probability estimates.

Strict Liability. The agent will choose $s$ and $x$ to maximize $u(s, x)=$ $u(s)-s x-s p^{i}(x) h$. Recall that if $\bar{p}$ is low enough, the agent will choose $x^{i}=x^{\star}$. Otherwise, the agent will choose $x^{i}=x^{\prime}$. Let us consider the two cases separately.

In the first case, where the agent chooses $x^{i}=x^{\star}$, the agent internalizes the expected harm, and thus acts the same as the rational agent. Thus, he chooses $s^{i}=s^{\star}$.

In the second case, where the agent chooses $x^{i}=x^{\prime}$, the agent's utility function is, in effect, $u(s)-s x^{i}$. The reason is that at $x^{i}=x^{\prime}$, the agent treats the probability of the accident, and thus the expected accident cost, as though it were zero. Thus the agent will choose $s^{i}$ such that $u^{\prime}(s)=x^{i}=x^{\prime}=(h / \bar{p})^{1 / 2}$. Intuitively, the agent will choose $s^{i} \geq s^{\star}$, because the only internalized cost of his activity is the level of care, and not the expected accident cost.

proof. In the second case the agent chooses $x^{i}=x^{\prime}$ because he has more than low optimism: $\bar{p} \geq 0.27 h^{1 / 3}$. Manipulating the inequality, we get $(h / \bar{p})^{1 / 2} \leq(3 h)^{1 / 3} / 2^{2 / 3}$. The left side of the inequality is $u^{\prime}\left(s^{i}\right)$, and

${ }^{4}$ Shavell, Economic Analysis of Accident Law at 41 (cited in note 2). 
the right side is $u^{\prime}\left(s^{\star}\right)$, as we saw above. Thus $u^{\prime}\left(s^{i}\right) \leq u^{\prime}\left(s^{\star}\right)$. Because $u^{\prime \prime}(s)<0, s^{i} \geq s^{\star}$.

This shows that the optimistic agent will engage in too much activity as long as $\bar{p}$ is not too low. The reason is that he will simply not take account of some of the cost (low probability harms) that he inflicts on others. For arbitrarily low values of $\bar{p}$, the agent will engage in the optimal level of activity. Thus, for a sufficiently broad distribution of $\bar{p}$, strict liability results in too much activity.

Negligence. Under negligence, the rational agent will choose $s$ and $x$ to maximize $u(s)-s x$. Thus, he will choose $s^{\star}$ to maximize $u^{\prime}(s)-x^{\star}$. Because the agent does not internalize the expected cost of accidents if he takes due care, he will engage in too much activity. ${ }^{5}$

The optimistic agent will choose $s$ and $x$ to maximize $u(s)-s x^{i}$, where, as before, we assume that the agent believes that the court will apply $x^{i}$ as the standard of care. In the low optimism case, where $x^{i}=x^{*}$, the agent will act the same as the rational agent and choose $s^{i}=s^{\star}$.

In the second case, where $x^{i}=x^{\prime}$, the agent will choose $s^{i}$ to maximize $u(s)-\bar{p}^{-1 / 2}$. Thus, the agent will choose the same high level of activity as under strict liability. ${ }^{6}$

We can summarize the results as follows. (1) When the agent is sufficiently optimistic, strict liability and negligence will have the same effect on activity. When the agent's optimism is at a low level, strict liability produces efficient activity and negligence produces too much activity, just as they do for the rational agent. (2) Under strict liability and negligence, the sufficiently optimistic agent might engage in too much care as well as too little care ( $x^{i}$ could be greater, less than, or equal to $\left.x^{\star}\right)$, and he will engage in too much activity $\left(s^{i}>s^{\star}\right)$. The point is that if the agent treats low probability events as though they will not occur, he will (usually) act like a rational agent under a negligence regime, where no liability is attached to careful behavior that causes expected harms.

\section{Level of Harm.}

It is clear from Table 1 that the level of harm will affect the chances that the agent will take the optimal level of care, or too much or too little. As harm increases, the agent is more likely to take the optimal level of care; more likely to take too much care; and less likely to take too little care. It is worth mentioning that one would get a different result if one assumed harm-insensitive optimism. The analogous table is:

\footnotetext{
${ }^{5}$ Id.

${ }^{6}$ This assumes that the agent believes the court will choose $x^{i}$ as due care; if not the moderate optimism case becomes the same as the low optimism case, as explained above.
} 
Table 2

\begin{tabular}{lll}
\hline Low Optimism & Moderate Optimism & High Optimism \\
\hline $\begin{array}{l}\bar{p} \leq 0.27 h^{-2 / 3} \\
x^{i}=x^{*}\end{array}$ & $0.27 h^{-2 / 3}<\bar{p}<0.63 h^{-2 / 3}$ & $0.63 h^{-2 / 3} \leq \bar{p}$ \\
Optimal Care & $x^{i}=x^{\prime}>x^{*}$ & $x^{i}=x^{\prime} \leq x^{*}$ \\
& Too Much Care & Too Little Care \\
\hline
\end{tabular}

Now, as harm increases, the agent is less likely to take the optimal level of care; more likely to take too much care; and more likely to take too little care.

The optimal level of care increases with harm. The harm-insensitive optimist will not internalize the increase in harm, while the harmsensitive optimist will internalize it partially. This is why an increase in harm will cause the harm-sensitive optimist to act more efficiently than the harm-insensitive optimist.

Figure 5 shows care as a function of harm. The curve labeled $x^{*}(h)$ depicts optimal care rising at a declining rate with the level of harm. The curve labeled $x^{i}(h)$ depicts irrational care. Note that it matches $x^{\star}(h)$ at high levels of harm; otherwise it is too low or too high except when the curves cross. The curve labeled $x^{i i}(h)$ shows harm-insensitive care, which of course is a horizontal line, invariant with respect to $h$, except at high levels of harm.

Figure 5 also shows how courts, in theory, could adjust awards in order to give efficient incentives to optimists. Focusing on the harm-sensitive case (the court can't affect the behavior of the harminsensitive agent except at high levels of harm), where the level of harm is roughly in the middle of the $x$-axis, the court could provide

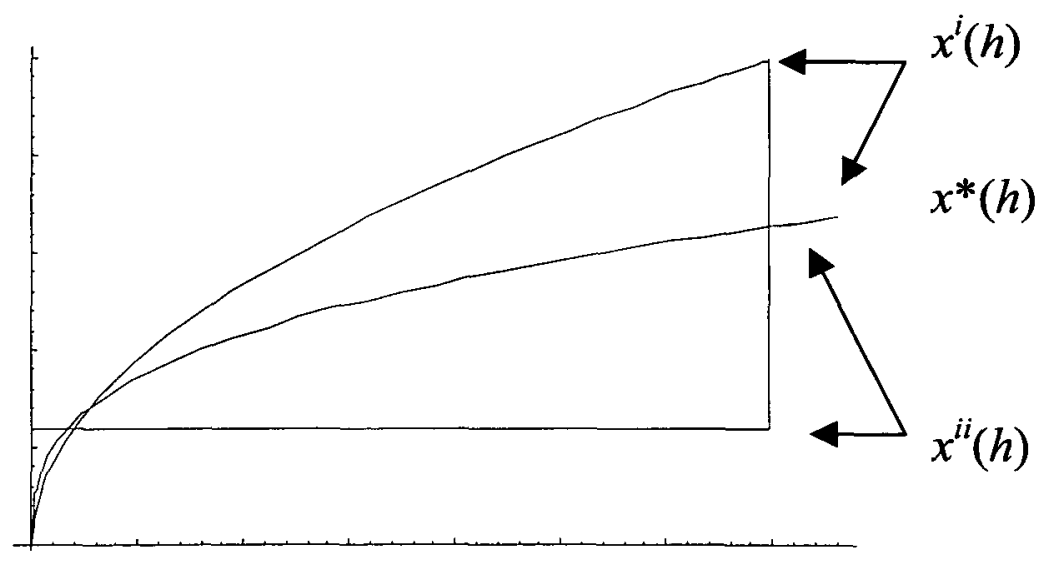

Figure 5. 
efficient incentives either by reducing the award or by increasing the award. If the award is reduced, the agent will take a level of care that is optimal for a rational agent but below optimal for the optimist. If the award is increased enough, the agent will be thrust into the region of the midlevel optimist, and act as though he were rational. This result holds in the region of midlevel optimism (where $x^{i}(h)$ and $x^{*}(h)$ cross on the left, and join on the right). At a higher level of optimism, the court should increase the award; at a lower level of optimism, the court does not need to adjust the award.

\section{Generality: Alternative Probability Distributions.}

One objection to the analysis so far is that the assumed probability distribution (or class of probability distributions) is implausible. It does not seem likely that when a person drives a car, he accurately estimates the probability of an accident as long as he takes little care, but then when his care exceeds a threshold, he then inaccurately thinks that the probability of an accident is zero. Indeed, the evidence for optimism is mixed, and other evidence suggests that in some settings people overestimate the probability of a small harm.

However, my results do not depend on people believing that low probabilities are zero or even that they optimistically underestimate probabilities. My results can hold even if people are pessimistic, and overestimate the probability of a small harm. The necessary assumption is only that people are insufficiently sensitive to probabilities.

One might think, for example, that the agent's subjective probability could be a step function. The agent thinks that for a range of lower care behavior the probability of an accident is the same high number; for a range of medium care behavior the probability of an accident is the same middle number; and for a range of low care behavior the probability of an accident is low, though not necessarily zero. It remains the case that the agent could take too much or too little care. Too little care is easy to understand; too much care will occur as long as the perceived drop in probability occurs soon enough after the optimal level of care, that the decline in expected accident liability is greater than the increase in the cost of care. Thus, the result does not depend on a discontinuous probability function, just on the function having at least one inflection point and a sufficiently steep slope soon after the optimal level of care. Nor does the result depend on optimism; the tail of the step function (for example) could be higher than the tail of $p(x)$.

One other possibility is that people are optimistic, but that the optimism does not affect the slope of the objective probability function. Formally, $p^{i^{\prime}}(x)=p^{\prime}(x)$ and $p^{i}(x)<p(x)$ for all $x$. If $p(x)$ is a linear func- 
tion, for example, then $p^{i}(x)$ would be just a parallel line that is below $p(x)$. This assumption might seem to be the most natural, but it is inconsistent with the literature, which suggests that people are more likely to be wrong about low probability events than about high probability events. But even if we accepted this assumption, it has an interesting and unintuitive result, namely, that the agent would take the optimal level of care (neither too much nor too little) under both strict liability and negligence. The reason is that the marginal benefit of care remains the same if the slope does not change. Thus, the current tort system provides the correct incentives for care (although not for activity level) even if agents are optimistic.

\section{Bilateral Accidents.}

Suppose that the victim as well as the injurer can reduce the probability of an accident by taking care; thus $p(x, y)$. If both agents estimate probabilities correctly, then strict liability produces less efficient levels of care than negligence does. Both rules cause the injurer to take optimal care; but full compensation under strict liability gives the victim no incentive to take care. Negligence, by contrast, makes the victim bear the cost of his own carelessness when the injurer takes due care but the accident occurs anyway. ${ }^{7}$

Now suppose that both parties are optimistic. As we saw before, the injurer will take the same level of care under both rules. Putting aside for the moment the level of care, the first thing to see is that the effect of the two rules on the victim remains the same: the victim will have no incentive to take care under strict liability, and will have such an incentive under negligence. Now returning to the question of level of care, the injurer could take too much or too little care; the victim under the negligence regime will also take too much or too little care, both because the victim himself is optimistic, and because the victim's choice will be affected by the inefficient level of care chosen by the injurer. ${ }^{8}$

As to the question of activity level, for rational agents strict liability with a defense of contributory negligence causes victims to engage in too much activity; negligence causes injurers to engage in too much activity. ${ }^{9}$ For sufficiently (midlevel or high level) optimistic

${ }^{7}$ See Brown, 2 J Legal Stud (cited note 3); Shavell, Economic Analysis of Accident Law (cited in note 2); Landes and Posner, The Economic Structure of Tort Law (cited in note 2).

${ }^{8}$ There are interesting variations that one could consider: suppose that victims are rational and mistakenly think that the injurer will choose $x^{*}$ rather than $\mathbf{x}^{\mathrm{i}}$. Or that the victims are rational but understand that injurers will choose $x^{i}$. One could also assume that the injurer is rational but the victim is optimistic, and so on.

${ }^{9}$ Shavell, Economic Analysis of Accident Law (cited in note 2). 
agents, under both rules victims and injurers will engage in too much activity. For strict liability with contributory negligence, the injurer will act as though he were governed by a negligence rule and not internalize accident costs above $x^{i}$. For negligence, the victim will act as though he will not incur accident costs above $y^{i}$. Thus, the two rules have the same behavioral effects, and the choice between the rules no longer matters.

\section{Insurance and Redistribution}

The argument so far illustrates some of the complex implications of probability estimation error for care and activity level. Here, I will briefly point out its implications for insurance and redistribution, focusing on optimism.

If people underestimate low probability events, they will buy too little insurance. But if they are optimistic, they might take too much, rather than too little, care. For example, rather than putting in too few smoke detectors because he is heavily insured, a homeowner might put in too many smoke detectors in order to reduce his perceived probability of a serious fire to zero. An insured optimist, then, might face less risk of fire than an insured person who is rational.

Jolls argues in a different context that optimism can justify redistributing wealth through the tort system. ${ }^{10}$ Because people underestimate low probability events, redistributive tort awards will distort neither their care nor their labor/leisure choice, and so will have a less negative effect than high taxes, which people can anticipate more easily and which distort their labor/leisure choice. In terms of the model, Jolls argues that the award should be $h+t$, where $t$ is the transfer, when the defendant is wealthy.

The problem is that increasing the award from $h$ to $h+t$ will distort behavior. To see why, look at Figure 5, and imagine that $h$ is the midpoint of the $\mathrm{x}$-axis. The optimist's level of care, $x^{i}(h)$ is already too high, and $x^{i}(h+t)$ would be even worse. The court could produce optimal care by reducing the award by some amount $r$, such that $x^{i}(h-r)=X^{\star}(h)$. Although there are cases where a positive transfer, $t$, would also reduce the distortion, Figure 5 provides no reason to think that awarding $t$ is anything but arbitrary, and in any event

${ }^{10}$ Christine Jolls, Behavioral Economics Analysis of Redistributive Legal Rules, 51 Vand L Rev 1653 (1998). Jolls' argument, as she acknowledges and discusses, depends on some assumptions, which are in my view questionable: that the stochastic loss won't be converted into a certain (small) loss through insurance, and that a "tax lottery" is not politically feasible. 
shows that redistributive tort awards can distort the care behavior of optimists. ${ }^{11}$

\section{SOME COMMENTS ON PROBABILITY ERRORS AND CONTRACT LAW}

The argument so far has implications outside tort law. Consider the following model of contract law. At time 1, Seller and Buyer enter an incomplete contract for the delivery of a good. Buyer has valuation, $v$. At time 2, Seller chooses a level of care, $x$. At time 3, Seller either performs or pays damages, $d$. Seller's cost is either 0 or, with probability $p(x)$, a high amount $c$, where $c>v$. We suppose that the market is competitive and Buyer pays a price $\pi$ equal to Seller's expected cost.

If transaction costs were zero and the parties could enter a complete contract, they would agree that Seller will take a level of care $x^{*}$ that minimizes the joint cost of care and loss to the Buyer $(v-\pi)$ that results if Seller does not perform. That is, $x^{\star}$ solves $\min p(x) v+x$. Buyer pays price $\pi=x^{\star}$ and earns a return of $v-x^{\star}$. Seller obtains a return of 0 . If transaction costs are positive and the parties cannot enter a complete contract that specifies $x^{\star}$, then the optimal level of damages is $v-\pi$, that is, expectation damages, which cause Seller to choose $x^{\star} \cdot{ }^{12}$

Suppose now that both Buyer and Seller are irrationally optimistic and think that the probability distribution is $p^{i}(x)$. The analysis is the same as in the tort case. A complete contract would specify $x^{i}$, which could be greater or less than $x^{\star}$; if the contract is incomplete and expectation damages is the remedy, the same result will be achieved. In addition, people will enter too many contracts because they will discount losses caused by low probability events (as before).

Suppose instead that Seller is rational at the time that he enters the contract but expects that he will be optimistic when he chooses $x$. If a complete contract is possible, he will want to include a provision requiring him to choose $x^{*}$ (and will hope that renegotiation is not possible at time 2 ). But verifiability problems will often prevent such a course of action: a court might not be able to determine $x^{\star}$. Another possibility is to agree to liquidated damages. If the Seller expects to choose $x^{i}<x^{\star}$, then he will want low liquidated damages; if

11 These problems can also complicate the analysis of transitions. For example, Kaplow assumes that if people underestimate the risks of a natural disaster like a flood, government supplied insurance would not distort incentives. See Louis Kaplow, An Economic Analysis of Legal Transitions, 99 Harv L Rev 509, 548 (1986).

${ }^{12}$ Robert Cooter and Thomas Ulen, Law and Economics 248-51 (Addison Wesley Longman, 3rd ed. 2000). 
he expects to choose $x^{i}>x^{*}$, then he will want high liquidated damages. The reason is that liquidated damages can be used to shift the $p^{i}(x) h$ curve up or down, in such a way as to cause the optimistic Seller at time 2 to choose $x^{*}$. This shows, contrary to much of the literature, that the existence of cognitive biases is not necessarily an argument for the penalty doctrine. ${ }^{13}$ Parties might agree to high liquidated damages in order to blunt the effects of optimism. ${ }^{14}$

\section{V. W E LFA R E}

In welfare economics, it is conventional to assume that the goal of the state is to maximize social welfare, which is some aggregation of the individual utility functions of all citizens.

Suppose that an agent prefers driving a car to taking a bus, but only because he underestimates the probability of a car crash. Should the state tax car driving in order to make the agent act the same way as he would if he knew the correct probability of the car crash? The legal literature answers this question positively, and a positive answer was implicitly assumed in the analysis in Parts I and II of this paper.

But the problem is more complex. To see why, consider the simplest case. Suppose that an agent engages in some activity that can injure only himself, and no one else. He is an optimist, and ignores the small chance that the activity will injure him. Suppose the government now mandates a precaution that reduces the low probability of an injury to zero. The agent will perceive this mandate as a cost, with no offsetting benefits. Therefore, his utility will decline, and so will the social welfare function. A welfare-maximizing government would therefore not impose what otherwise would seem to be a sensible mandate.

The problem also occurs in the more general tort case, whenever victims are optimistic. High tort awards designed to counter the wrongdoer's carelessness will not be experienced as an ex ante gain by the victim, and will not affect the victim's behavior. The insights of cognitive psychology-especially those relating to biases in perception and risk estimation-are not easily reconcilable with welfare economics, and thus cannot be straightforwardly imported into nor-

\footnotetext{
${ }^{13}$ The result is sensitive to the assumption that the probability function is discontinuous or has an inflexion point. Under more conventional assumptions (a smooth probability function], we get the opposite result: if $x^{i}<x^{*}$, Seller will choose high liquidated damages, and vice versa. But the basic point - that the existence of cognitive biases is not necessarily an argument for the penalty doctrine-remains valid. Rationally anticipating optimism, parties will sometimes choose high liquidated damages provisions. I thank Oren Bar-Gill for this point.

${ }^{14}$ Cf. Jeffrey I. Rachlinski, The "New" Law And Psychology: A Reply To Critics, Skeptics, and Cautious Supporters, 85 Cornell L Rev 739 (2000).
} 
mative law and economics. Many normative proposals made by authors writing within "behavioral law and economics" fail to address this problem.

This is not to say that the problem is insoluble. But solving it requires a conception of welfare different from the conception used by economics. One could imagine that welfare is objective in the sense that regardless of one's preferences one has less welfare if one unknowingly takes high risks than if one does not. Or welfare could involve not just having any preference, but the right kind of preferences, and when a person's preference for driving is not sufficiently informed, that preference does not fully count in the person's welfare. But these are difficult and complex problems that have not been resolved by economists and philosophers.

\section{CONCLUSION}

The most important methodological point I want to make is that when one tries to operationalize the insights of cognitive psychology, and make them usable for law and economics, one must make certain specific assumptions about the shape of probability functions, and terms like "optimism" are too vague to be of help. A person who underestimates low probability events might be called an optimist, but he also might be called a pessimist (in certain ranges) about the likelihood that more care will avoid accidents. The pessimist about care might act the same as the optimist about liability. The paper has explored various ways that probability errors can be formalized, and their implications for tort and contract law.

The paper also has some testable empirical implications. One might use psychological exams to test for optimism, and then see whether optimistic people take the same level of care under strict liability and under negligence, or whether optimistic people are more likely to take too much care under both rules than non-optimistic people are. The model also allows for indirect tests of optimism: if people are harm-sensitive, then they should take the optimal level of care when harm is low, higher levels of care when harm is moderate, and lower levels of care when harm is high. Indirect tests like these would be difficult, and open to multiple interpretations, but they might be a useful way for avoiding the problem of measuring optimism. 
HeinOnline -- 11 Sup. Ct. Econ. Rev. 1422003 